\title{
Perancangan Sistem Akuntansi Persediaan Dan Kartu Gudang Berbasis Komputer Pada Konveksi Tas
}

\author{
Endrawati \\ Firman Surya \\ Widio Putra Perta R. \\ Jurusan Akuntansi, Politeknik Negeri Padang
}

\begin{abstract}
Bag is one of commodities produced by local industries in Indonesia in general, and in particular western Sumatra. However, the company, has several weaknesses related to the management and recording of inventory such as the lack of segregation of duties and responsibilities by each section, management procedures and record-keeping supplies inadequate and the lack of documents and records that support the transactions related to inventory, This research aims to design a card inventory accounting system and computer-based warehouse that will be applied to the sales system, purchasing system and system of material usage to fit the elements contained in the internal control system. Based on research that has been done, then the inventory accounting system designed in accordance with the elements contained in the internal control systems and computer-based warehouse cards are useful for recording the transfer of inventory stored in warehouse. Besides being able to produce information that is far more accurate than manual recording, computer-based warehouse card is also used in the savings and effectiveness of the use of the document processing time.
\end{abstract}

Keywords: system, procedures, flowchart, stock card, microsoft access.

\section{PENDAHULUAN}

.Sebuah badan usaha didirikan tentunya karena si pendiri memiliki tujuan. Salah satu dari tujuan tersebut adalah untuk memperoleh laba agar usaha tersebut dapat bertahan dan memiliki sumber daya yang cukup untuk mencapai ragam tujuan lainnya. Untuk mendapatkan laba, perusahaan akan terlibat dalam banyak kegiatan bisnis. Misalnya, seorang pemilik akan mendirikan usaha konveksi tas, maka pengelola usaha akan terlibat dalam kegiatan menyewa tempat, membeli mesin dan peralatan jahit, menggaji penjahit dan tukang pola, membeli bahan baku pembuatan tas, membayar telepon dan listrik, menerima pesanan pelanggan serta menerima pembayaran dari pelanggan.

Kegiatan-kegiatan tersebut antara lain yang disebut sebagai proses bisnis. Proses bisnis merupakan sekumpulan kegiatan bisnis yang dilakukan oleh suatu perusahaan dalam usahanya untuk mendapatkan laba. Dalam suatu proses bisnis, tentunya harus memiliki sistem informasi akuntansi yang baik. Sistem informasi akuntansi memiliki peranan yang penting dalam proses bisnis karena sistem informasi akuntansi mengidentifikasi, mengukur, dan mencatat proses bisnis tersebut dalam suatu model yang sedemikian rupa sehingga informasi yang dihasilkan dapat dimanfaatkan oleh pihak-pihak yang berkepentingan (Anastasia Diana, 2011).

Pada era globalisasi dan informasi saat ini, perusahaan mengusahakan agar dapat menerapkan sistem yang baik untuk menunjang kegiatan operasional perusahaan kedepannya. Masih banyak Usaha Kecil dan Menengah (UKM) yang menggunakan sistem informasi akuntansi atas dokumen dan pencatatan secara manual. Perbandingan antara sistem informasi akuntansi manual dan terotomatisasi (berbasis komputer) terletak pada teknologi yang digunakan dan bagaimana keakuratan data output yang akan dihasilkan.

Salah satu sumber daya di dalam perusahaan yang harus menganut sistem informasi akuntansi yang baik adalah persediaan. Persediaan atau inventori yaitu barang-barang yang disimpan untuk digunakan atau dijual pada masa atau periode yang akan datang. Pengelolaan 
persediaan harus dilakukan dengan sistem dan prosedur yang memadai dan dikelola secara tepat agar tidak timbulnya kecurangan atau ketidakcocokan pada persediaan tersebut serta dengan adanya pengelolaan persediaan yang baik dan benar sehingga perusahaan tidak terbatasnya persediaan yang ada digudang atau tempat penyimpanan barang. Persediaan biasanya merupakan jumlah yang relatif besar dari aktiva lancar atau bahkan dari seluruh aktiva perusahaan.

Dalam perusahan dagang, persediaan hanya terdiri dari satu golongan, yaitu persediaan barang dagangan, yang merupakan barang yang dibeli untuk tujuan dijual kembali. Sedangkan dalam perusahan manufaktur dimana perusahaan mengolah bahan baku menjadi barang jadi, maka persediaan dikelompokkan pada persediaan barang jadi, persediaan barang dalam proses, persediaan bahan baku, persediaan bahan penolong, persediaan bahan habis pakai pabrik, persediaan suku cadang dan persediaan perlengkapan. Transaksi yang mengubah persediaan barang jadi, persediaan bahan baku, persediaan bahan penolong, persediaan bahan habis pakai pabrik, persediaan suku cadang, dan persediaan perlengkapan, bersangkutan dengan transaksi internal perusahaan dan transaksi yang menyangkut pihak luar perusahaan (penjualan dan pembelian), sedangkan transaksi yang mengubah persediaan barang dalam proses seluruhnya berupa transaksi internal perusahaan (Mulyadi, 2001).

Usaha Konveksi tas, rata-rata menghasilkan berbagai jenis tas, seperti tas seminar, tas lokakarya, tas pelatihan, tas kongres, tas muktamar, tas ransel dan tas salempang. Omzet perusahaan mulai dari Rp.50.000.000 sampai dengan $\mathrm{Rp}$ 80.000 .000 ,- perbulan. Persediaan yang terdapat di gudang cukup banyak yang terdiri dari persediaan bahan baku, persediaan bahan penolong, dan persediaan barang jadi yang beragam jenis. Sistem akuntansi persediaan yang ada pada saat ini belum memiliki pengendalian yang baik dan benar. Hal ini dapat dilihat pada pengelolaan dan pencatatan persediaannya. Contohnya perusahaan menumpuk persediaan begitu saja di gudang sehingga menyebabkan kesulitan pada saat mencari barang yang diinginkan, permintaan barang jadi dari fungsi penjualan ke fungsi gudang dilakukan tanpa adanya bukti yang mendukung kegiatan tersebut sehingga tidak adanya pencatatan saat barang jadi keluar dari gudang, dan pengelolaan persediaan pada saat adanya transaksi pemakaian bahan atas prosedur permintaan dan pengeluaran bahan gudang dari fungsi produksi ke fungsi gudang tidak melibatkan fungsi gudang sehingga tidak terlihat adanya mutasi bahan keluar dari gudang.

Oleh karena itu, perusahaan
membutuhkan kartu gudang berbasis komputer dengan tujuan untuk memperkecil kemungkinan salah catat dan adanya transaksi harian yang terlewatkan untuk dicatat jika menggunakan kartu gudang berbasis komputer. Kondisi perusahaan yang sudah menggunakan sistem komputer untuk mendukung kegiatan operasional perusahaan juga menjadi dasar pertimbangan penulis untuk merekomendasikan adanya penggunaan kartu gudang berbasis komputer ini. Untuk merancang kartu gudang berbasis komputer, penulis akan menggunakan Microsoft Access 2007 karena aplikasi ini mudah dimengerti dan dipahami serta laporan persediaan yang tersedia akan lebih informatif sebagai bukti untuk melihat adanya mutasi barang masuk dan barang keluar di bagian gudang.

\section{METODE PENELITIAN}

Penelitian ini menggunakan metode analisis kualitatif deskriptif berbasis case study, yaitu menggambarkan kondisi sesungguhnya yang terjadi di lapangan (perusahaan) untuk menjadi dasar dalam perancangan system. Tahap penelitian dilakukan mulai dari analisis pendahuluan, pengumpulan data, perancangan system, dan uji coba serta evaluasi hasil.

\section{PERANCANGAN SISTEM AKUNTANSI PERSEDIAAN DAN KARTU GUDANG BERBASIS KOMPUTER PADA KONVEKSI TAS}


Dokumen yang digunakan untuk menyusun laporan keuangan Home-Industry Sala Lauak sebagai berikut;

\subsection{Survey Pendahuluan}

Dari suvey penduluan diperoleh beberapa informasi terkait kekurangan perusahaan, antara lain perusahaan belum memiliki;

a. Catatan atas stok persediaan yang ada digudang baik persediaan bahan baku, bahan penolong maupun barang jadi. Maka dari itu diperlukan adanya kartu gudang berbasis komputer yang berguna untuk lebih mempermudah mengetahui adanya transaksi barang masuk, keluar dan tersisa di gudang yang nantinya akan dicatat oleh Bagian Gudang.

b. Dokumen pendukung atas semua transaksi yang terkait dengan persediaan baik penjualan, pembelian maupun pemakaian bahan seperti Memo Permintaan Barang, Form Pesanan Produk, Perintah Produksi, Form Pengambilan Bahan, Surat Permintaan Pembelian dan Laporan Produk Selesai.

c. Pencatatan jurnal akuntansi atas semua transaksi yang terkait dengan persediaan baik penjualan, pembelian maupun pemakaian bahan dan pencatatan pada transaksi penjualan hanya dicatat dalam buku manual penerimaan kas perusahaan yang dilakukan oleh Manager.

d. Nomor urut tercetak dalam dokumen yang saat ini dimiliki perusahaan yaitu Faktur Penjualan dan Nota Pesanan.

\subsection{Perancangan system Akuntansi persediaan}

\subsubsection{Prosedur Penjualan Langsung}

Pada gambar 1, dapat diliha prosedur penjualan langsung. Prosedur ini melibatkan bagian penjualan, gudang, dan manager.
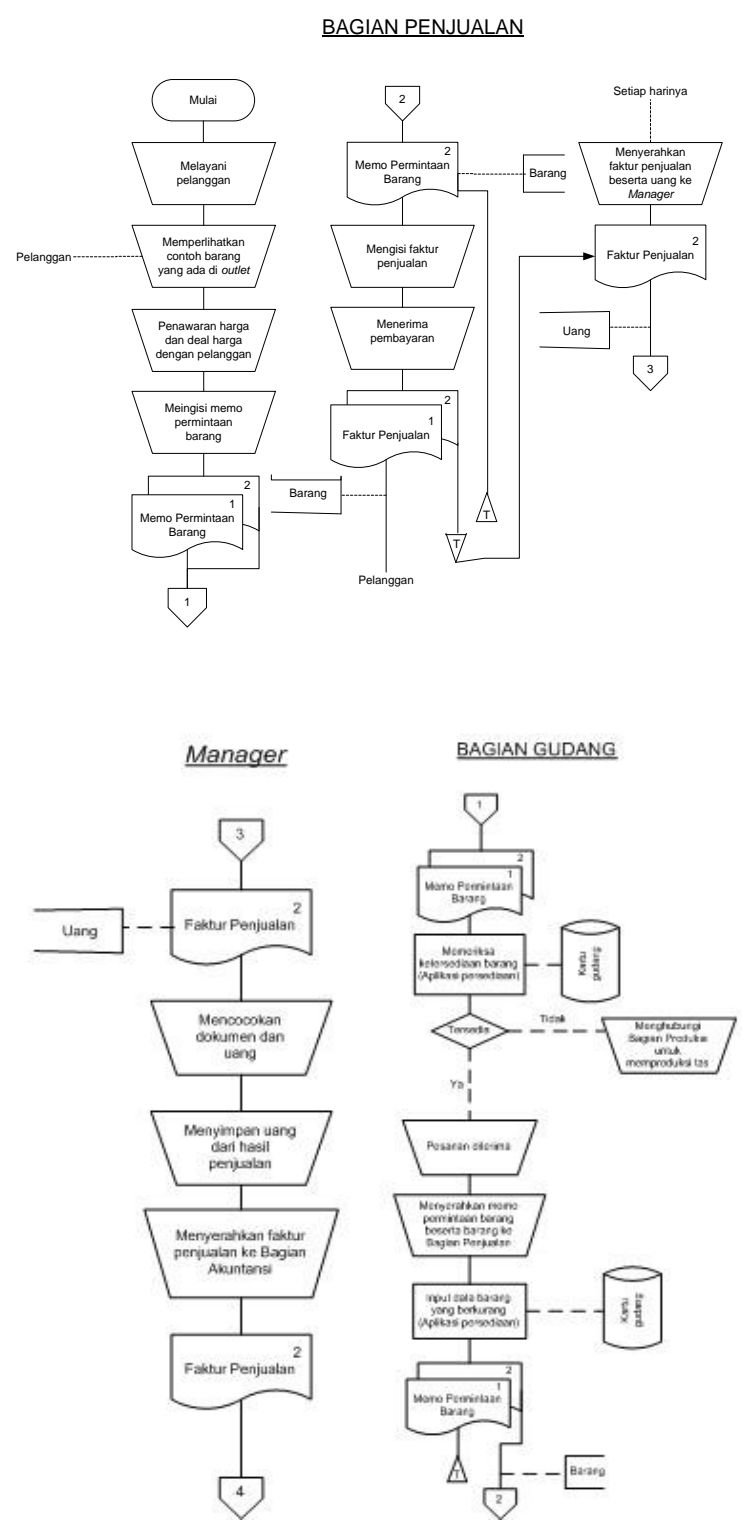

Gambar 1. Siklus penjualan langsung (tanpa pesanan)

\subsubsection{Prosedur Penjualan Pesanan}

Pada gambar 2, dapat diliha prosedur penjualan pesanan yang dilakukan perusahaan. Prosedur ini melibatkan bagian penjualan, produksi, gudang, dan akuntansi. 
Perancangan Sistem Akuntansi Persediaan dan Kartu Gudang Berbasis Komputer
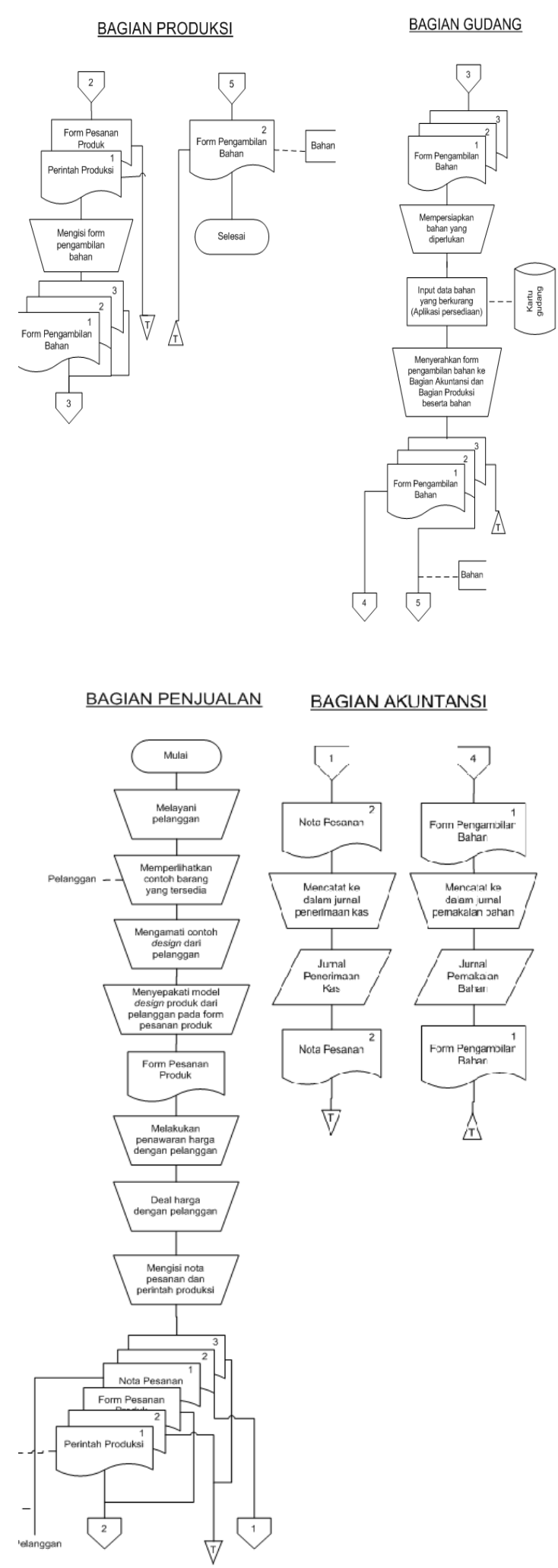

Gambar 2, Prosedur penjualan pesanan
Pada gambar 3, dapat dilihat prosedur pembelian bahan baku. Prosedur ini melibatkan bagian gudang, pembelian dan transportasi dan bagian akuntansi. BAGIAN GUDANG BAGIAN PEMBELLAN DAN TRANSPORTAS

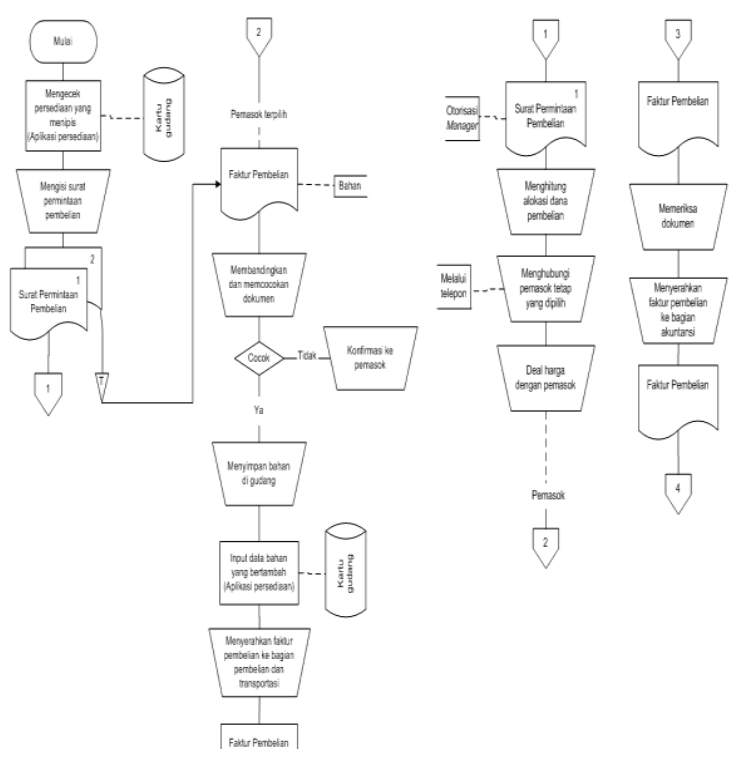

BAGIAN AKUNTANSI

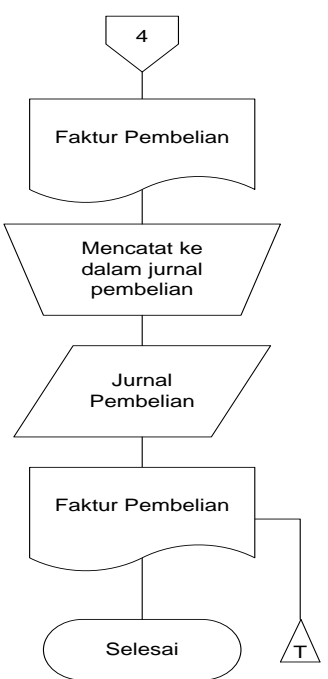

3.2.4. Prosedur Pemakaian Bahan

Pada gambar 4, dapat dilihat prosedur pemakaian bahan baku yang dilakukan perusahaan. Prosedur ini melibatkan bagian produksi, Gudang dan bagian akuntansi.

\subsubsection{Posedur Pembelian Bahan Baku}




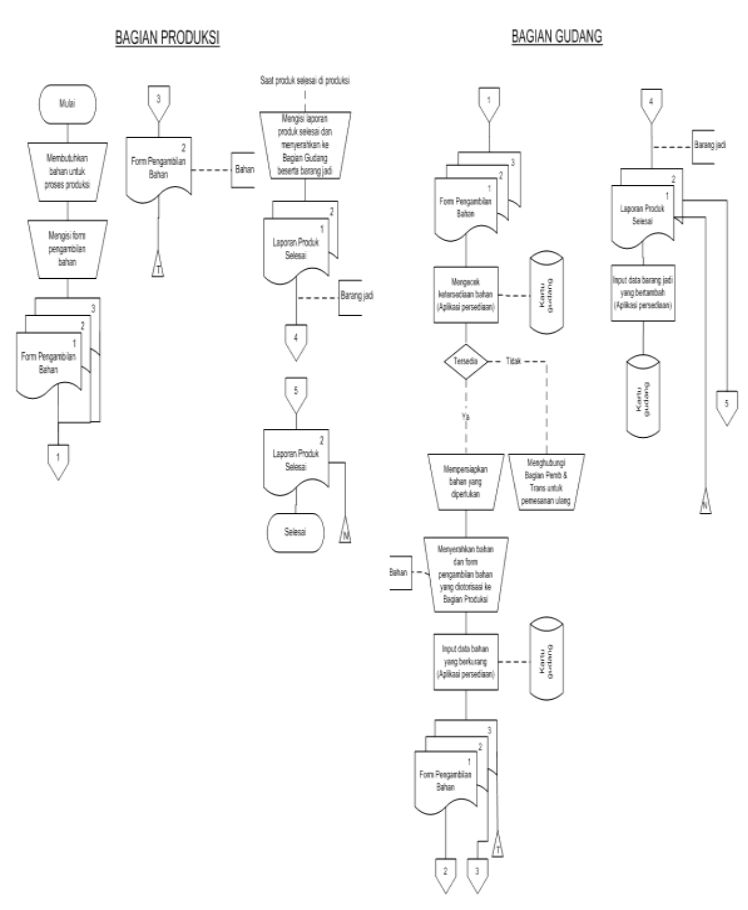

BAGIAN AKUNTANSI

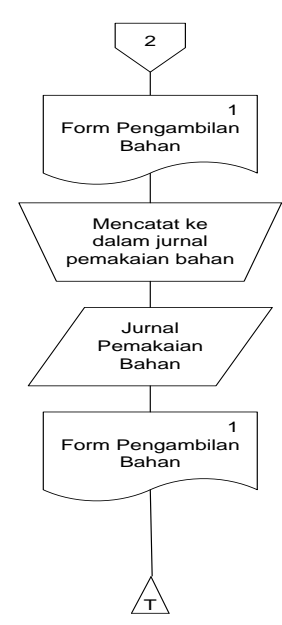

\subsection{Perancangan Kartu Gudang Berbasis Komputer}

\subsubsection{Perancangan Relationship}

Pada gambar 5, dapat dilihat perancangan relationship tabel kartu persediaan.

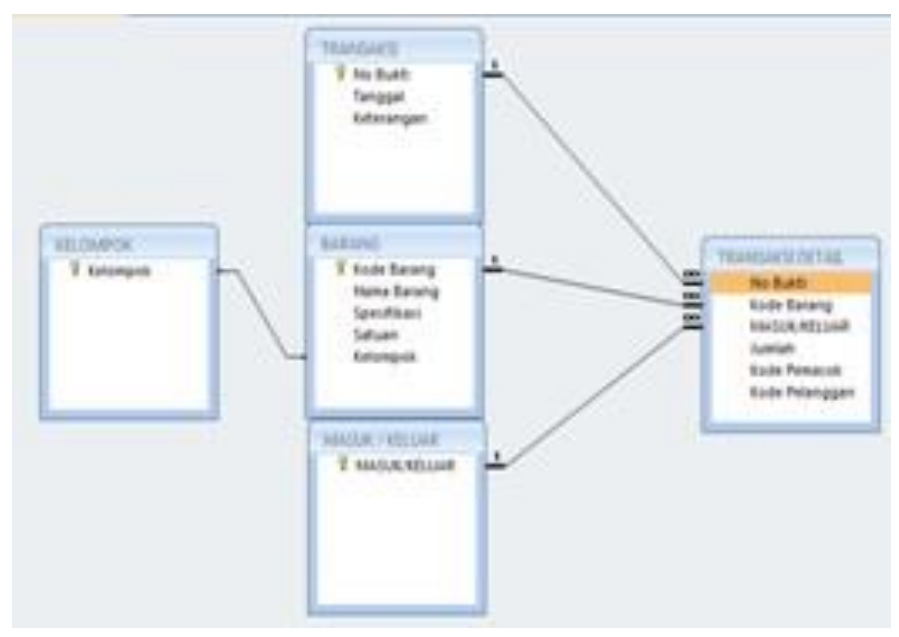

\subsubsection{Perancangan Field Query}

Pada gambar 6, dapat dilihat perancangan query tabel kartu persediaan.

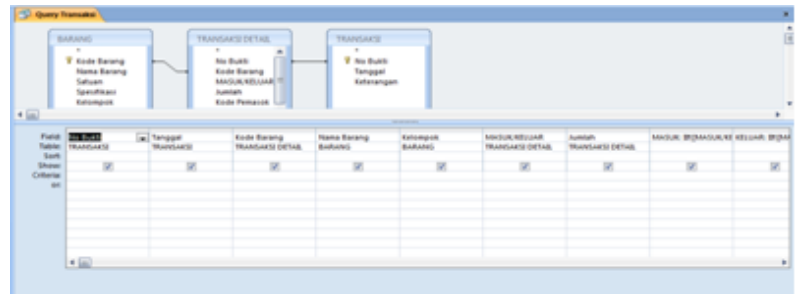

\subsubsection{Perancangan Form}

a) Form Daftar Barang

b) Form Transaksi

\subsubsection{Report / Laporan}
a. Report Barang Masuk
b. Report Barang Keluar
c. Report Transaksi
d. Report Stok Bahan Baku
e. Report Stok Bahan Penolong 
Perancangan Sistem Akuntansi Persediaan dan Kartu Gudang Berbasis Komputer

f. Report Stok Barang Jadi

\section{g. Report Rekapan Barang}

\section{KESIMPULAN DAN SARAN}

\subsection{KESIMPULAN}

Dari uraian pada bab-bab sebelumnya, penulis dapat menyimpulkan bahwa:

a. Konveksi Tas merupakan perusahaan manufaktur dengan memproduksi berbagai macam jenis tas dan perusahaan dagang denganmenjual berbagai macam perlengkapan seni rupa dan grafika. Persediaan yang dimiliki oleh Konveksi Tasyang terletak di gudang sangat banyak yang terdiri dari persediaan bahan baku, bahan penolong dan barang jadi.

b. Konveksi Tas belum menerapkan Sistem Akuntansi Persediaan yang sesuai dengan unsur-unsur yang terdapat pada sistem pengendalian internal pada saat melaksanakanprosedur kegiatannya seperti belum ada pemisahan fungsi dan tanggung jawab antara masingmasing bagian.

c. Konveksi Tas belum menerapkan pengelolaan persediaan digudang dengan baik dan benar terbukti dengan tidak adanya kartu gudang untuk merekam adanya mutasi barang masuk dan barang keluar yang ada digudang.

d. Konveksi Tastidak memiliki catatan untuk mendukungseluruhkegiatan yang terkait dengan sistem penjualan, sistem pembelian dan sistem pemakaian bahan.Perusahaan hanya menggunakan buku manual penerimaan kas untuk melakukan pencatatan penjualan baik secara langsung maupun pesanan.

e. Konveksi Tas belum memakai dokumen-dokumen pendukung yang berguna untuk merekam pelaksanaan pengelolaan dan pencatatan persediaan. Dokumen yang digunakan hanya Nota Pesanan dan Faktur Penjualan pada saat adanya transaksi penjualan baik langsung maupun pesanan.

\subsection{SARAN}

Adapun saran yang dapat penulis berikan untuk Konveksi Tas yaitu :

a. Sebaiknya perusahaan memakai kartu gudang berbasis komputer yang penulis rancang dengan menggunakan Microsoft Access 2007 untuk memudahkan dalam menginput transaksi yang mempengaruhi persediaan dan waktu yang digunakan relatif cepat dari pekerjaan manual.

b. Sebaiknya perusahaan memisahkan fungsi tanggungjawab dan wewenang untuk setiap bagian dengan menambahkan Bagian Gudang, Bagian Pembelian dan Transportasi serta Bagian Akuntansi agar tidak terjadinya rangkap fungsi jabatan oleh masingmasing bagian.

c. Sebaiknya perusahaan melaksanakan Sistem Akuntansi Persediaan yang sesuai dengan unsur-unsur yang terdapat pada sistem pengendalian internal sebagaimana yang penulis rekomendasikan dalam pemecahan masalah.

\section{DAFTAR REFERENSI}

Arfan, Ikhsan (2009). Pengantar Praktis Akuntansi. Yogyakarta: GRAHA ILMU.

Baridwan, Zaki. 2002. Sistem Akuntansi Penyusunan Prosedur dan Metode. Yogyakarta: BPFE

Diana, Anatasia dan Lilis (2011). Sistem Informasi Akuntansi. Yogyakarta: ANDI.

Endrawati dkk (2011). Database Manajemen dan Akuntansi. Edisi 2. Padang. Politeknik Negeri Padang. 
Perancangan Sistem Akuntansi Persediaan dan Kartu Gudang Berbasis Komputer

Horngren, Charles T. 1996. Akuntansi di Indonesia. Jakarta : Salemba Empat

Imam Heryanto (2012). Membuat Database dengan Microsoft Access. Edisi Revisi. Bandung: Informatika Bandung.

Muhlis, Ahmad dan Anggraini (2015). Aplikasi Toko, Akuntansi, dan Penggajian dengan Access 2010. Jakarta: PT Elex Media Komputindo.

Mulyadi. 2001. Sistem Akuntansi. Yogyakarta. Salemba Empat

Psychologymania (2013). Metode Penilaian Persediaan. Ditelusuri 20 Agustus 2015.http://www.psychologymania.co $\mathrm{m} / 2013 / 01 /$ metode-penilaianpersediaan.html

Soemarso, SR 2004. Akuntansi Suatu Pengantar. Buku Satu, Edisi 5 (revisi). Jakarta : Salemba Empat

Widjajanto, Nugroho. 2001. Sistem Informasi Akuntansi. Jakarta: Erlangga 